\title{
Diagnostic Tests for The Control of Foot and Mouth Disease: An Overview
}

LAZARUS, D. D*., ADAMU, S. S., FASINA, F. O.

Viral Research Division, National Veterinary Research Institute, P.M.B. 01, Vom, Plateau State Nigeria

*Corresponding author: lazdav2003@yahoo.co.uk, Phone number: +234 (0) 7036176910

\section{SUMMARY}

Foot and mouth disease (FMD) is a major trans-boundary animal disease (TAD) that has a great potential for causing severe economic loss in susceptible cloven-hoofed animals. This paper describes the various diagnostic tests available for FMD, the limitations of each and their potential application in a low technology setting. The need to have complementary field and laboratory operations including suitable samples and transport methods are discussed, and examples are given. The importance of a quality assurance system to assess the accuracy and precision of diagnostic results is highlighted.

Keywords: Foot and mouth disease, Transboundary, Diagnostic tests, Quality assurance.

\section{INTRODUCTION}

Livestock is very important in the agriculturally based, resource poor economies and social structures of subSaharan Africa. Endemic and periodically epidemic foot and mouth disease (FMD) has serious impact on food security (including crop production through its effect on draught animals), rural income generation and national economies by impairing livestock trade. Consequently, the poorest sectors of the community are most seriously affected. The progressive control of FMD is both a national priority and regional imperative (Khounsy et al., 2008). FMD is the most contagious disease of mammals and can cause severe economic losses in susceptible cloven-hoofed animals. While the disease usually does not cause high level of mortality, it results in productivity losses and induces lameness and its attendant severely limited use of cattle and buffalo for traction, which is of major importance to the livelihoods of poor farmers.

\section{CLINICAL DIAGNOSIS}

Clinical signs of FMD vary widely between species. In cattle, onset of FMD is usually characterized by pyrexia, anorexia and sometimes shivering, followed by smacking of the lips, grinding of the teeth, drooling, lameness and stamping or kicking of the feet. These symptoms are caused by vesicles on the buccal and nasal mucous membranes and /or between the claws and coronary band that will rupture, leaving erosions (OIE, 2009). Recovery generally occurs within 8-15 days although complications can include superinfection of lesions with bacteria or screw-worm infestation, hoof deformation, myocarditis, abortion, death of young animals and permanent loss of weight. Post mortem lesions on rumen pillars and in the myocardium, particularly in young animals (tiger heart), may be evident. In sheep and goats, the lesions are less pronounced and foot lesions may go unnoticed. Pigs may develop severe foot lesions, particularly when housed on concrete, and there may be high mortality in piglets (OIE, 2009). The differential diagnosis is species dependent and includes vesicular stomatitis, swine vesicular disease and vesicular exanthema of swine, which are all clinically indistinguishable from FMD. In view of the differentials, a sound laboratory based diagnosis is therefore a confirmatory tool in the diagnosis of FMD. 


\section{LABORATORY DIAGNOSIS Antigen and Virus Detection methods Virus Isolation}

FMD virus will grow in a wide range of primary and continuous in-vitro cell cultures. The most sensitive cell culture for the isolation of FMDV is primary bovine thyroid (BTY) cells (House and House 1989). Continuous cell lines such as baby hamster kidney (BHK), lamb kidney (LK) and the pig kidney cell line IB-RS-2 and MVPK-1 are also susceptible to FMDV infection. The sensitivity of virus isolation will depend on the quality and type of cells used as well as the quality of the sample (Morrissy et al., 2008).

\section{Antigen capture ELISA}

The Antigen Capture (AC)-ELISA or serotyping ELISA is the test of choice for countries endemic with FMD and is the recommended test for the detection of FMD antigen (OIE, 2008). The FMD AC-ELISA provides detection of FMD antigens and identification of serotypes in the case of an FMD positive sample, and was developed in its current form by Roeder and Le Blanc Smith, (1987).

The FMD AC-ELISA replaced the complement fixation test for primary FMD diagnosis and serotype identification because of its increased specificity and sensitivity and because it is not affected by pro- or anti-complementary factors in the test sample (Ferris and Dawson 1988). Standard reagents for the FMD AC-ELISA are produced at the World Reference Laboratory (WRL) for FMD, Pirbright, United Kingdom.

Sample quality is important as lesions older than 4-5 days have less antigens; however, samples unsuitable for virus isolation can be tested by ELISA. The ELISA allows high throughput testing of samples and is well suited to low technology settings. Higher throughput can be achieved with robotics and other equipment and is mainly used in large laboratories which can afford to purchase and maintain this capability (Morrissy et al., 2008).

\section{Molecular Techniques}

In the years since the advent of genetic diagnostic techniques nearly two decades ago, more than 50 different nucleic acid hybridization and various PCR technologies have been reported for the diagnosis of FMD (Reid et al., 2002). Recently, real time PCR methods (Taq Man, molecular beacons, Primer-Probe Energy Transfer System) have been developed for FMD diagnosis and are now the mainstay for FMD genetic diagnosis (Reid et al., 2002; Oem et al., 2005; Wieslaw et al., 2010). Evaluation of real time PCR methods with conventional diagnostics (Shaw et al., 2004; Ferris et al., 2006) concluded that PCR was generally more sensitive and rapid, and is ideal for samples which contain low concentrations of virus. By introducing nucleic acid extraction and pipetting robotics, together with multichannel real time PCR machines, diagnostic procedures have become rapid, robust and automated but may not be best suited to low technology settings. Another promising development for the developing country laboratories is the one-step, reverse transcription loop-mediated amplification (RT-LAMP) assay, which enables FMD virus to be detected in under 1 hour in a single tube without thermal cycling (Dukes et al., 2006; Jun-Jun et al., 2010).

\section{Antibody Detection Methods. Liquid Phase Blocking \& Competitive ELISA}

The FMD liquid phase blocking (LP)-ELISA was developed for the detection of FMD antibodies because of the drawbacks of the conventional virus neutralization tests (VNTs), which included slowness of the tests (up to 3 days), the use of live virus and cell cultures, and the difficulty in reproducing results, all which could be countered by the 
use of ELISA (Morrissy et al., 2008). The FMD LP-ELISA can detect antibodies against all seven FMD serotypes using polyclonal rabbit and guinea pig IgG antibodies to detect residual FMD antigen following invitro incubation of test serum and FMD antigen (the "liquid phase"). Result from the FMD LP-ELISA indicated high degree of correlation with VNT results for post infection and vaccinated animals, and it was suggested to be a suitable alternative to the VNT. It was also suggested that the FMD LPELISA could be used to estimate in-vitro protection to FMD challenge (Hamblin et al, 1986a, 1986b, 1987).

The FMD LP-ELISA is one of the recommended ELISA methods for the detection of FMD antibodies (OIE, 2008) and is the primary test for determining vaccine titres, as it is being used in some laboratories. Recently, the FMD competitive (C)-ELISA has been developed for all seven serotypes of FMD in response to the issue of FMD LP-ELISA being less conducive to a large scale testing and automation. The FMD c-ELISA was developed using the same reagents as the FMD LP-ELISA, but without the "liquid phase" step, allowing a result in the same day (4-5 hours). The FMD c-ELISA was found to be more robust, sensitive and specific than the FMD LP-ELISA, and was used in the recent UK FMD outbreak to allow rapid screening of serum samples for FMD antibodies (Morrissy et al., 2008).

\section{FMD non-structural protein assays}

Viral replication in FMD infected animals induces an immune response against the non-structural (NS) protein of the FMD. The response against NS protein is not serotype specific and indicates infection with any of the seven serotypes. Animals which are not infected with FMD but vaccinated normally do not develop a detectable antibody response against NS protein in the ELISA. Nevertheless, repeatedly applied, low quality vaccines, (e.g. lack of viral inactivation and purification) may induce a false positive result in this test. In these cases, the history from the field, e.g. about potential outbreaks/infection, identification of vaccine and number of vaccinations received, is important for correct interpretation of the result.

The use of vaccine for the control of FMD has led to the development of a number of assays for the detection of NS antibodies to discriminate between vaccinated animals and those that have been infected. Australian Animal Health Laboratory, with the support of International Atomic Energy Agency, has developed an in-house FMD NS 3ABC c-ELISA (Morrissy et al., 2007). It uses baculovirus expressed $3 \mathrm{ABC}$ antigen and a competing antibody, which is produced in chicken. This ELISA has been used and validated in Asia (IAEA, 2007). There are a number of commercial ELISA kits available including the baculovirus $3 \mathrm{ABC}$ expressed antigen from CEDI Diagnostics, the E. coli $3 A B C$ expressed antigen from Bommeli and the synthetic $3 \mathrm{~B}$ antigen from UBI (de Bronsvoort et al., 2004). There are possibilities of others at different stages of development and in-house ELISAs are also available in some laboratories. The CEDI diagnostics kit and the AAHL kit are both competitive ELISAs that can be used for all species, whereas the other kits are indirect ELISAs with separate kits for ruminants and pigs. The CEDI diagnostics kit has been found to be the most sensitive and specific (Brocchi et al., 2006). However, comparisons between the kits from CEDI and AAHL have shown that both ELISAs have similar performance characteristics.

\section{QUALITY ASSURANCE AND QUALITY CONTROL}

"Quality is fitness for the intended purpose: Quality assurance is a system designed to assure test facility management of compliance with a quality standard, e.g. AS ISO 17025-2005" General requirements for 
the competence of testing and calibration laboratories. Quality control is the technical realization of the quality assurance concept, e.g. calibration, assay validation, precision and accuracy of test results. Quality assurance and quality control principles are crucial requirements to comply with quality standards such as ISO 17025-2005 or the OIE's "Quality Standard and guidelines for Veterinary laboratories: Infectious disease" (De Clercq et al., 2008).

The key components of quality assurance with regards to FMD diagnosis are:

- Paper work/documentation of all tests into standard protocols.

- Validation data for diagnostic tests being used in the laboratory.

- Staff training and accreditation.

- Internal quality control (IQC) -positive and negative controls included in each test run.

- Analysis and charting to document results from IQC controls used in each test.

- External quality assurance -successful participation in proficiency test rounds.

- Documentation on all sample collection, storage and transport from the field, and storage and handling in the laboratory.

- Calibration of equipment and calibration records.

- Laboratory accreditation to a standard e.g. ISO 17025-2005.

Quality control of the FMD diagnostic tests is achieved through a combination of internal quality control and external quality assurance. Repeatability and reproducibility are measurements of precision and results are of particular value to monitor the validity of test results (De Clercq et al., 2008).

Internal quality control is useful to measure the repeatability of test results in a laboratory. Ideally, internal controls should be included as replicates in each test run and should cover at least the critical range of test results to be expected, e.g. strong positive control $(\mathrm{C}++)$; weak positive control, which is slightly above the cut-off $(\mathrm{C}+)$; and negative control. Analysis of internal quality control will give information about intraand inter-assay variations, intra- and interoperator variation, day to day variation etc. Critical parameters are basic statistics such as mean values, standard deviation, coefficient of variation, range and upper and lower control limits. Results can be charted and recorded as Levey-Jennings charts. This approach helps to identify trends in assay performance and is useful to prompt preventive corrective actions or trouble shooting. Internal quality control data can also be useful to access measurement of uncertainty, e.g. continued measurement of replicates of internal positive control close to the cut-off (De Clercq et al., 2008).

External quality assurance or proficiency testing measures the reproducibility of a test and its performance in different laboratories. It helps to standardize test results for the same test in different laboratories (inter-laboratory comparison, ring test or external quality assurance) or to harmonize test results from different tests in different laboratories (proficiency test round). Successful and regular participation approximately twice a year in external quality assurance programmes is an essential component of ISO 17025-2005 or OIE quality standard requirements, and therefore a pre-condition for accreditation (De Clercq et al., 2008).

Equipment calibration and maintenance is another important part of quality assurance because it helps to ensure that tests are giving correct results. It is important that laboratories have a budget to allow them to maintain and calibrate their equipment. In summary, quality assurance and quality control are crucial elements in a laboratory's quality system and need to be well 
established to achieve accreditation to internationally accepted standards.

\section{CONCLUSION}

Effective diagnosis and control of livestock diseases requires a strong animal health network where laboratory staff, field veterinarians and epidemiologists work together. Laboratories contributing to the diagnostic network must be able to carry out diagnosis with OIE recommended or alternative tests within a recognized quality assurance system. OIE reference laboratories play important roles in monitoring disease situation in a country and ensuring that continued, updated and accurate information is forwarded to OIE. This is especially important with TADs, zoonotic, and new and emerging diseases because of their global threat.

The laboratory network in a country is made up of laboratories at different levels of standard and capability, from the national laboratory down to the province and district levels. The diagnostic tests used in these laboratories will differ according to their respective capabilities.

The national laboratory may have the full range of diagnostic tests, which includes virus isolation and a molecular capability for PCR and sequencing, whereas a provincial or district laboratory will most probably have low-cost technology. Tests such as ELISAs are the most routinely used for FMD antibody and antigen detection. ELISAs are cheaper to run than virus isolation and PCR but reagents and equipment are still expensive for laboratories in poorer

\section{REFERENCES}

BROCCHI E., BERGMANN I.E., DEKKER A., PATON D.J., SAMMIN D.J., GREINER M., GRAZIOLI S., De SIMONE F., YADIN H., HAAS B., BULUT N., MALIRAT V., NEITZERT E., GORIS N., PARIDA S., SØRENSEN K and De CLERCQ, K ( 2006): Comparative evaluation of six ELISAs for countries or at the district level.

For FMD serology the LP-ELISA is the test of choice in a country where FMD is endemic, as it is still the only test validated for post vaccination testing. The c-ELISA is used in FMD-free countries, and can be used to screen sera first as it has greater sensitivity, specificity and allows greater throughput. The NS-ELISA is used with the structural LPELISA or the c-ELISA to distinguish infected animals from vaccinated. The NS-ELISA does not identify carrier animals, but rather animals that have been infected with FMDV in the past. The NS-ELISA can be used to indicate disease prevalence or when a country is declaring freedom from FMD or in animal trading to indicate that animals have not been exposed to FMDV. The AC-ELISA is used for detection of FMD antigen and is the only test able to rapidly determine the serotype of an FMD outbreak. PCR is important as a confirmation for FMD genome and in further characterization of FMDV by sequencing. Virus isolation is important in producing high-titred stocks of FMDV for characterization or for growth of samples with low virus titre. Virus isolation is used in national or reference laboratories due to the high cost of maintaining tissue culture.

Overall, the quality of samples submitted to the laboratory is of utmost importance in achieving precise and accurate results and it involves: maintaining a cold chain, collection of appropriate samples for diagnosis, and collection in the appropriate sample collection buffer (i.e. phosphate/glycerol for virus isolation and ELISA).

the detection of antibodies to the nonstructural proteins of foot-and-mouth disease virus. Vaccine 24, 6966-6979.

De BRONSVOORT B.M.C., SØRENSEN K.J., ANDERSON J., CORTEYN A., TANYA V.N., KITCHING R.P. and MORGAN K.L (2004): Comparison of two 3ABC enzyme-linked immunosorbent assays for diagnosis of 
multiple-serotype foot-and-mouth disease in a cattle population in an area of endemicity. J. Clin. Microbiol. 42 (5), 2108-2114.

DE CLERCQ K., GORIS N., BARNETT P.V. and Mac KAY D.K (2008): The importance of quality assurance/quality control of diagnostics to increase the confidence in global foot-and-mouth disease control. Transboundary Emerg. Dis. 55, 35-45.

DUKES J.P., KING D.P. and ALEXANDERSEN S (2006): Novel reverse transcription loopmediated isothermal amplification for rapid detection of foot-and-mouth disease virus. Arch. Virol. 151, 1093-1106.

FERRIS N.P. and DAWSON M (1988): Routine application of enzyme-linked immunosorbent assay in comparison with complement fixation for the diagnosis of foot-and-mouth and swine vesicular diseases. Vet. Microbiol. 16, 201-209.

FERRIS N.P., KING D.P. and REID S.M (2006): Comparisons of original laboratory results and retrospective analysis by real-time reverse transcriptase-PCR of virological samples collected from confirmed cases of foot-and-mouth disease in the UK in 2001. Vet. Rec. 159, 373-378.

HAMBLIN C., BARNETT I.T.R. and CROWTHER J.R. (1986a): A new enzyme-linked immunosorbent assay (ELISA) for the detection of antibodies against foot-and-mouth disease virus. II, Application. J. Immunol. Methods. 93, 123-129.

HAMBLIN C., BARNETT I.T.R. and HEDGER R.S. (1986b): A new enzyme-linked immunosorbent assay (ELISA) for the detection of antibodies against foot-andmouth disease virus. I, Development and method of ELISA. J. Immunol. Methods. 93, 115-121.

HAMBLIN C, KITCHING R.P., DONALDSON A. I., CROWTHER J. R. and BARNETT I.T.R. (1987): Enzyme linked immunosorbent assay (ELISA) for the detection of antibodies against foot-and-mouth disease virus. III, Evaluation of antibodies after infection and vaccination. Epidemiol. Infect. 99, 733-744.

HOUSE C. and HOUSE J.A. (1989): Evaluation of techniques to demonstrate foot-and-mouth disease virus in bovine tongue epithelium: Comparison of the sensitivity of cattle, mice, primary cell cultures, cryopreserved cell cultures and established cell lines. Vet. Microbiol. 20, 99-109.

IAEA TECHNICAL DOCUMENT 1546. (2007). The use of non-structural proteins of footand-mouth disease virus (FMDV) to differentiate between vaccinated and infected animals. Available at: http://www-naweb.iaea.org/nafa/aph/public/te_1546_web.pdf. Accessed on $11^{\text {th }}$ September, 2009.

JUN-JUN S., HIN-YUN C., GUANG-QING Z., GUO-ZHENG C., JUN-ZHENG D., TONG LIN., SHAN-DIAN G., JI-JUN H., XIANG TAO L., JI-XING L., JIN-LIANG G. (2010): Rapid Detection of Foot-and-Mouth Disease Virus by Reverse Transcription Loop-mediated Isothermal Amplification (RT-LAMP). Intern. J Appl Res Vet Med. Vol. 8, No. 2, 2010.

KHOUNSY S., CONLAN J.V., GLEESON L.J., WESTBURY H.A., COLLING A., PATON D.J., KNOWLES N.J., FERRIS N.P. and BLACKSELL S.D. (2008): Foot-and-mouth disease in Lao PDR: I, A review of recent outbreaks and lessons from control programme. Rev. Sci. tech. off. Int. Epiz. 27 (3), 839-49.

MORRISSY C.J., Mc EACHERN J., COLLING A., WRIGHT L., LONG N.T., GOFF W., HAMMOND J., JOHNSON M., CROWTHER J.R., HOA D.M. and DANIELS P. (2007): International validation of a new 3ABC competitive ELISA for FMD serology. Proceedings of World Association of Veterinary Laboratory Diagnosticians $13^{\text {th }}$ International Symposium, Melbourne, Australia, 12-14 November, 2007.

MORRISSY C, WRIGHT L, CONLAN J, GOFF $\mathrm{W}$, A COLLING, J HAMMOND, $\mathrm{M}$ JOHNSON, S BLACKSELL and P DANIELS (2008). Diagnostic tests for the control of classical swine fever and foot-and-mouth disease in South-East Asia: An overview. Proceedings of an International Workshop held in Vientiane, Lao PDR, 20-21 November 2006.

OEM J.K., KYE S.J. and LEE K.N. (2005): Development of a lightcycler-based reverse transcription polymerase chain reaction for the detection of foot-andmouth disease virus. J. Vet. Sci. 6, 207212.

WIESLAW NIEDBALSKI and ANDRZEJ KESY 
(2010): Rapid detection and quantification of foot-and-mouth disease virus by a real-time reverse transcription PCR. Bull. Vet. Inst. Pulawy 54, 3-7.

OIE-World Organisation for Animal Health (2008): Foot-and-mouth disease. In: Chapter 2.1.5 "Manual of diagnostic tests and vaccines for terrestrial animals (mammals, birds and bee)". Available at: http//www.oie.int. Accessed on $3^{\text {rd }}$ February, 2009.

OIE-World Organisation for Animal Health (2009): Technical Disease Cards: Foot and mouth disease.

REID S.M., FERRIS N.P. and HUTCHING G.H. (2002): Detection of all seven serotypes of foot-and-mouth disease virus by realtime, fluorogenic reverse transcription polymerase chain reaction assay. $J$. Virol. Methods 105, 67-80.

ROEDER P.L. and Le BLANC SMITH P.M. (1987): Detection and typing of foot-andmouth disease virus by enzyme-linked immunosorbent assay: a sensitive, rapid and reliable technique for primary diagnosis. Res. Vet. Sci. 43, 225-232.

SHAW A.E., REID S.M. and KING D.P. (2004): Enhanced laboratory diagnosis of footand-mouth disease by real-time polymerase chain reaction. Rev. Sci. tech. Off. Int. Epiz. 23, 1003-1009. 